Conclusions Our study suggests that PE in COVID-19 is more common in males and in those with COVID symptoms greater than 2 weeks, high oxygen requirements and highly elevated D-dimers. There should be a low threshold for investigating such patients for PE. Moreover, we found COVID-19 patients with PE have high likelihood of having a bilateral pulmonary distribution with right heart strain.

\section{P88 INITIAL ROUTINE LABORATORY TESTS CAN BE USED TO PREDICT CLINICAL COURSE IN PATIENTS HOSPITALISED WITH COVID-19}

RL Young, KV Mullins, A Ainley. Barking, Havering and Redbridge University Hospitals NHS Trust, Romford, Essex, UK

\subsection{6/thorax-2021-BTSabstracts. 198}

Background Previous work has related demographic and clinical characteristics to clinical course and outcome of patients hospitalised with COVID-19. ${ }^{1}$ We sought to evaluate if initial routine laboratory test results could be utilised to predict length of inpatient stay (LOS), need for non-invasive (NIV)/ invasive mechanical ventilation (IMV) and admission to an intensive care unit (ICU). We also sought to establish if Creactive protein levels related to radiographic disease severity.

Methods A retrospective analysis was carried out on a cohort of 567 patients with a laboratory confirmed diagnosis of COVID-19 admitted during the second wave of the pandemic between April 2020 and May 2021 including descriptive statistics and multivariate and regression analysis. Radiological severity was based upon previously proposed scoring systems. ${ }^{2}$ Results Of the 567 patients included, 342 (60\%) were male, mean age 61 years, 318 (56\%) were Caucasian, 143 (25\%) Asian and 35 (6\%) Black. Raised admission d-dimer and urea levels correlated with longer LOS $(r=0.17$ and 0.16 respectively, $p<0.01$ ). Rising C-reactive protein and d-dimer correlated with increased risk of requirement for admission to ICU $(r=0.27$ and 0.19 respectively, $p<0.001)$, need for NIV (Pearson's correlation 0.26 and 0.15 respectively, $\mathrm{P}<0.01)$ and progression to IMV $(\mathrm{r}=0.15$ and $0.14, p<0.05)$. A correlation between initial routine blood results and death was not detected. C-reactive protein correlated with radiographic disease severity $(\mathrm{r}=0.32, p<0.001)$.

Conclusions Abnormalities in initial laboratory test results may be utilised to risk stratify patients presenting to secondary and tertiary care with COVID-19, may help predict clinical course and in doing so facilitate more efficient and streamlined delivery of care and resource utilisation with likely significant impact on patient outcomes.

\section{REFERENCES}

1. Cheng D, Calderwood C, Skyllberg E, et al. Clinical characteristics and outcomes of adult patients admitted with COVID-19 in East London: a retrospective cohort analysis. BMJ Open Respiratory Research 2021;8:e000813.

2. Monaco CG, Zaottini F, Schiaffino $S$, et al. Chest $x$-ray severity score in COVID-19 patients on emergency department admission: a two-centre study. Eur Radiol Exp. 2020;4(1):68

\section{P89 VITAMIN D DEFICIENCY INCREASES SUSCEPTIBILITY TO COVID-19 INFECTION}

S Kumar, R Ragatha, S Waring, G Gamtkitsulashvili, A D'Souza, M Mahenthiran, S Tan, M Parsons, S Visuvanathan, A Sefton, U Ekeowa, P Russell. The Princess Alexandra Hospital, Harlow, Essex, UK

10.1136/thorax-2021-BTSabstracts. 199
Background Vitamin D plays a vital part in modulating the immune system, with Vitamin D deficiency leading to increased susceptibility to infection. ${ }^{1}$ There is some evidence to suggest Vitamin D may play a protective role in the prevention of COVID-19 infection in hospitalised patients, ${ }^{2}$ but the topic remains controversial. Our study aims to investigate if low Vitamin D levels correlate with increased risk of COVID-19 infection, thereby representing a modifiable risk factor for COVID-19 infection.

Method A retrospective observational study was conducted on 3198 health care workers of a Greater London District General Hospital, who had undergone testing for 25-OH Vitamin D levels and COVID-19 antibody in June 2020. In accordance with NICE guidelines, Vitamin D deficiency was defined as less than $25 \mathrm{nmol} / \mathrm{L}$, insufficiency as $25-50 \mathrm{nmol} / \mathrm{L}$, and those with levels over $50 \mathrm{nmol} / \mathrm{L}$ were used as control comparisons. Evidence of previous SARS-CoV-2 infection was assessed by detection of SARS-CoV-2 IgG antibodies. Regression analysis was performed to determine independent significance, accounting for age and gender.

Results 3191 participants were included in this study, with age ranging from 19-78 years (mean 42.9) of which 78.2\% were female. Both age and gender were not independently associated with positive SARS-CoV-2 IgG antibodies. 1997 (62.6\%) participants had Vitamin D levels within the normal range, 899 (28.2\%) participants had insufficient levels and 302 (9.4\%) had Vitamin D deficiency. Both Vitamin D deficiency (OR 1.61, $p=0.002$ ) and insufficiency (OR 1.33, $p=0.006$ ) independently correlated with significantly increased incidence of positive COVID-19 antibodies than personnel with normal Vitamin D levels.

Conclusions We report the largest single-centre study investigating the impact of low Vitamin D levels within healthcare workers to date. Significant correlation between low levels of Vitamin D and previous COVID-19 infection was identified. Oral Vitamin D supplementation to maintain levels $>50$ nmol/L may play a protective role against COVID-19. Larger studies are needed to investigate the role of Vitamin D supplementation in healthcare workers for further COVID-19 waves.

\section{REFERENCES}

1. Aranow C, et al. Journal of Investigative Medicine 2011;59:881-886.

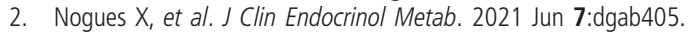

\section{P90 USE OF PROCALCITONIN TO PREDICT MORBIDITY AND MORTALITY IN COVID-19}

S Kumar, A D'Souza, G Gamtkitsulashvili, S Waring, Y Narayan, G Collins, O Taylor, S Jiwani, K Patrick, A Sethuraman, S Naik, S Kuckreja, R Ragatha, M Anwar, U Ekeowa, P Russell. The Princess Alexandra Hospital, Harlow, Essex, UK

\subsection{6/thorax-2021-BTSabstracts.200}

Background Procalcitonin (PCT) is an established biomarker of acute bacterial infection, and elevated levels of PCT may correlate with increased severity in patients with COVID-19 infection. ${ }^{1}$ Here, we assess if initial PCT levels are a viable prognostic marker to predict significant morbidity and mortality outcomes for hospitalised patients admitted due to COVID-19 infection.

Method We performed retrospective analysis of initial blood results taken from 1189 patients with RT-PCR positive COVID-19 infection presenting to our District General 


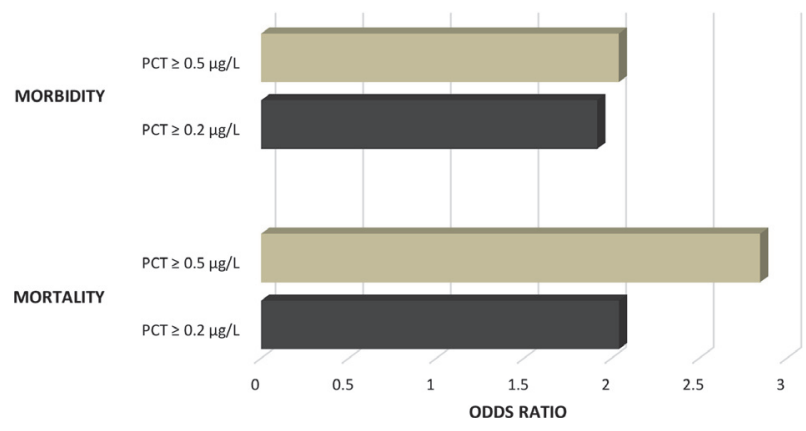

Abstract P90 Figure 1 The association of PCT in COVID-19 and patient morbidity and mortality.

Hospital between 1st November 2020 and 28th February 2021. Mortality encompassed both inpatient and within 28 days post-discharge. Significant morbidity was defined as admission to the Intensive Care Unit (ICU) for organ support. PCT was measured using Brahm's chemiluminescent micro particle assay (CMIA). Elevated PCT was defined at two levels: PCT $\geq 0.5 \mu \mathrm{g} / \mathrm{L}$ and PCT $\geq 0.2 \mu \mathrm{g} / \mathrm{L}$, to account for variance amongst literature. ${ }^{2}$ Regression analysis was performed to determine independent significance, accounting for comorbidity and demographics.

Results We found elevated PCT levels conferred a significant two-fold increase in mortality and ICU admission. Initial PCT $\geq 0.5 \mu \mathrm{g} / \mathrm{L}$ was associated with a significantly increased risk of mortality than those with PCT $<0.5 \mu \mathrm{g} / \mathrm{L}$ $(46.5 \%$ vs $24.2 \%$; OR 2.847, $\mathrm{p}=0.0001)$. Significantly higher mortality risk was also observed when using lower cut-off values, i.e, PCT $\geq 0.2 \mu \mathrm{g} / \mathrm{L}$ vs PCT $<0.2 \mu \mathrm{g} / \mathrm{L} \quad(\mathrm{OR}$ 2.042, $\mathrm{p}=0.00001)$. A significantly higher rate of ICU admission for initial PCT $\geq 0.5 \mu \mathrm{g} / \mathrm{L}$ (OR 2.041, $\mathrm{p}=0.007$ ) or $\mathrm{PCT} \geq 0.2 \mu \mathrm{g} / \mathrm{L} \quad(\mathrm{OR} 1.918, \quad \mathrm{p}=0.0008)$ was also observed within our cohort.

Conclusions Here, we report the largest single-centre study to date in analysing a UK-based population for procalcitonin in COVID-19. We observed a significant correlation between elevated initial levels of PCT and incidence of ICU admission and mortality within our cohort, thereby demonstrating promise for PCT as an effective prognostic marker. Using a higher cut-off for PCT $\geq 0.5 \mu \mathrm{g} / \mathrm{L}$ increased mortality by almost $50 \%$, but had no effect on morbidity. We suggest that a lower universal cut-off point for PCT should be used for detecting secondary bacterial infections and procalcitonin-guided antimicrobial therapy.

\section{REFERENCES}

1. Hu R, et al. International Journal of Antimicrobial Agents 2020;56(2):106051.

2. Vazzana N, et al. Acta Clin Belg. 2020 Sep 23:1-5.

\section{P91 IMPACT OF BACTERIAL INFECTIONS IN PATIENTS WITH COVID-19 ON MORBIDITY AND MORTALITY DURING THE SECOND UK SARS-COV-2 WAVE}

S Waring, G Gamtkitsulashvili, S Kumar, Y Narayan, A D'Souza, S Jiwani, O Taylor, G Collins, K Patrick, A Sethuraman, S Naik, S Kuckreja, R Ragatha, M Anwar, U Ekeowa, P Russell. The Princess Alexandra Hospital, Harlow, Essex, UK

10.1136/thorax-2021-BTSabstracts.201
Background Bacterial infection has previously been observed in only $8 \%$ of COVID-19 patients, ${ }^{1}$ yet antibiotics are administered to $85 \%$ of inpatients. Typically, Gram negative organisms and Staphylococcus aureus are isolated as responsible pathogens. ${ }^{2}$ Here, we investigate the rates of bacterial infection during the second UK COVID-19 wave, its sources, the responsible organisms, and its impact on morbidity and mortality.

Methods 1342 RT-PCR positive COVID-19 patients admitted to a Greater London District General Hospital between 1st November 2020 and 28th February 2021 were retrospectively analysed (44.6\% female; mean age 68.8; mortality 26.9\%). Mortality encompassed hospitalised patients and those up to 28 days post-discharge. Morbidity was assessed by length-ofstay and need for intensive care. Positive cultures due to contaminants were excluded. Independent correlation was assessed with multilinear regression analysis adjusting for demographics and comorbidities.

Results 226 patients (16.8\%) with COVID-19 had $\geq 1$ bacterial infection. These patients possessed significantly higher independent mortality $(35.0 \%$ vs. $25.3 \%, \mathrm{p}<0.009)$, more frequently required intensive care support $(19.5 \%$ vs $10.6 \%$, $\mathrm{p}<0.00004)$, and required longer inpatient spells (19.6 days vs 9.46 days, $p<0.0001)$. Greater number of positive culture types cumulatively increased mean length-of-stay (OR 9.08, $\mathrm{p}<0.00001) ; \geq 2$ culture type positivity $(\mathrm{n}=44)$ related to 31.5 days; $\geq 3$ culture type positivity $(n=12) 46.0$ days. There was significantly higher mortality rate in patients receiving $\geq 1$ antibiotic (30.2\%) compared to no antibiotics $(6.4 \%$, $\mathrm{p}<0.00001)$.

Conclusion Bacterial infection is observed far more frequently in COVID-19 patients than previously reported and adversely affects morbidity and mortality. Multiple sites of bacterial infection prolongs inpatient stay and increases mortality. Thorough culture collection should be encouraged in COVID-19 patients with biochemical evidence of bacterial infection to identify responsible pathogens and respective antimicrobial sensitivity. Given the higher mortality rates, empirical use of antibiotics in COVID-19 patients without supporting evidence of bacterial infection is strongly discouraged.

\section{REFERENCES}

1. Lansbury, et al. J Infect. 2020 Aug;81(2):266-2.

2. Russell C, et al. Lancet Microbe. 2021 Jun 2. https://doi.org/10.1016/S2666-5247 (21)00090-2

Abstract P91 Table 1 (a) Most frequently observed bacterial species (b) Culture type positivity with relation to rates of mortality

\begin{tabular}{|c|c|c|c|c|c|}
\hline $\begin{array}{l}\text { (a) } \\
\text { Bacteria }\end{array}$ & $\begin{array}{l}\text { Number } \\
\text { isolated }\end{array}$ & $\begin{array}{l}\text { (b) } \\
\text { Culture Type }\end{array}$ & $\begin{array}{l}\text { Number of } \\
\text { positives }\end{array}$ & $\begin{array}{l}\text { Number of } \\
\text { deaths }\end{array}$ & $\begin{array}{l}\text { Positivity } \\
\text { mortality }\end{array}$ \\
\hline Enterococcus & 67 & Urine & 104 & 28 & $26.9 \%$ \\
\hline Escherichia & 65 & Blood & 76 & 28 & $36.8 \%$ \\
\hline Staphylococcus & 64 & Skin & 40 & 16 & $40 \%$ \\
\hline Pseudomonas & 24 & $\begin{array}{l}\text { Sputum \& } \\
\text { BAL }\end{array}$ & 33 & 20 & $60.6 \%$ \\
\hline Klebsiella & 12 & Stool & 13 & 5 & $38.5 \%$ \\
\hline Streptococcus & 12 & $\begin{array}{l}\text { Central } \\
\text { venous line }\end{array}$ & 8 & 4 & $50 \%$ \\
\hline
\end{tabular}

 